\title{
Temporal trends of transcatheter aortic valve implantation in a high-volume academic center over 10 years
}

\author{
Zenon Huczek*, Bartosz Rymuza ${ }^{* *}$, Maciej Mazurek', Radosław Wilimski², Piotr Scisło', Karol Zbroński', \\ Kajetan Grodecki', Szymon Jędrzejczyk', Ewa Pędzich-Placha', Piotr Hendzel², Krzysztof J Filipiak', \\ Grzegorz Opolski', Janusz Kochman'
}

${ }^{1} 1^{\text {st }}$ Department of Cardiology, Medical University of Warsaw, Warszawa, Poland
${ }^{2}$ Department of Cardiosurgery, Medical University of Warsaw, Warszawa, Poland
*Both authors equally contributed to the study.

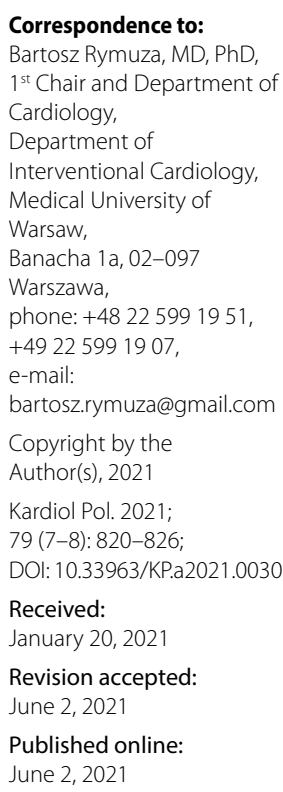

Correspondence to: Bartosz Rymuza, MD, PhD,

$1^{\text {st }}$ Chair and Department of Cardiology,

Department of

Interventional Cardiology

Medical University of

Warsaw,

Banacha 1a, 02-097

Warszawa,

phone: +48 225991951

+49225991907.

e-mail:

bartosz.rymuza@gmail.com

Copyright by the

Author(s), 2021

Kardiol Pol. 2021;

79 (7-8): 820-826;

DOI: $10.33963 /$ KP.a2021.0030

Received:

January 20, 2021

Revision accepted:

June 2, 2021

Published online:

June 2, 2021

\begin{abstract}
A B S TRACT
Background: Indications for transcatheter aortic valve implantation (TAVI) have gradually expanded since its introduction.

Aims: The aim was to analyze temporal trends in TAVI characteristics based on the experience of a high-volume academic center over the period of 10 years.

Methods: Five hundred and six consecutive $(n=506)$ patients with 1-year follow-up were divided into early (G1, years 2010-2013, $n=130)$, intermediate $(G 2,2014-2016, n=164)$ and recent $(G 3,2017-2019$, $\mathrm{n}=212$ ) experience groups.
\end{abstract}

Results: Patient's age remained constant over time (mean [SD]; G1 $=79.1$ [7.1] years vs G2 $=79.1$ [7.1] years vs $G 3=79.7$ [6.6] years, $P=0.73$ ) but surgical risk in $G 3$ was lower (log Euroscore, median [IQR]: $\mathrm{G} 1=14.0[8.4-20.2]$ vs $\mathrm{G} 2=12.0[7.0-22.2]$ vs $\mathrm{G} 3=5.1$ [3.5-8.5]; $P<0.001)$. Major/life-threatening bleeding (G1 $=26.9 \%$ vs $G 2=12.8 \%$ vs G3 $=9.4 \% ; P<0.001)$, major vascular complications $(G 1=15.4 \%$ vs $\mathrm{G} 2=8.5 \%$ vs $\mathrm{G} 3=5.7 \% ; P=0.02)$ and moderate/severe paravalvular leak (G1 $=16.2 \%$ vs $\mathrm{G} 2=11 \%$ vs $\mathrm{G} 3=7.5 \% ; P=0.046$ ) were decreasing with time. There was a significant drop in all-cause 1-year mortality in $\mathrm{G} 3(\mathrm{G} 1=20 \%$ vs $\mathrm{G} 2=17.7 \%$ vs $\mathrm{G} 3=9.1 \%$; log rank $=0.01)$.

Conclusions: The age of TAVI recipients remained unchanged over the last decade. Decreasing surgical risk coupled with improvements in procedural technique and care resulted in fewer periprocedural complications and better 1-year survival.

Key words: TAVI, low-risk population, 1-year mortality, stroke, bleeding complications

Kardiol Pol 2021; 79, 7-8: 820-826

\section{INTRODUCTION}

Transcatheter aortic valve implantation (TAVI) is currently the least invasive procedure available for the definitive treatment of severe symptomatic aortic stenosis (AS). Initially, it has been a highly specialized procedure, carried out only in a few selected academic centers in Poland, and only on inoperable, highest risk patients [1-3]. As time went by, due to positive results from large randomized trials, TAVI was recognized for a broader population of AS patients in European guidelines on the management of valvular heart disease and subsequently became more routine [4-8].

While the standards of care were changing, the number of TAVI procedures in Poland grew slowly but steadily from its introduction in 2008. Parallel to guidelines modifica- tions, improvements in bioprothesis design and function, and changes in procedural technique and periprocedural management of patients were observed. Therefore, the aim of the study was to analyze temporal trends in baseline characteristics, procedural as well as clinical outcomes of patients treated with TAVI based on the experience of a high-volume polish academic center over the period of 10 years.

\section{METHODS}

\section{Study population}

For the purpose of the study we included 506 consecutive patients who received TAVI from March 2010 to July 


\section{WHAT'S NEW?}

Transcatheter aortic valve implantation (TAVI) has grown from an innovative intervention reserved only for highest-risk or inoperable patients with severe aortic stenosis AS into an almost default procedure in elderly patients irrespective of baseline risk. However, the age of TAVI patients remained unchanged over the last decade and did not add to the overall risk reduction. Decreasing surgical risk coupled with improvements in delivery systems, bioprosthesis design, implantation technique, and periprocedural care resulted in fewer complications and better 1-year survival in the 2017-2019 group.

2019 and who gave their informed consent to enter Transcatheter Valve Treatment Sentinel Registry (2010-2012), which later was continued by the national POL-TAVI registry database $[9,10]$. Data concerning patients' characteristics and periprocedural outcomes were gathered prospectively. All patients completed a 12-month follow-up, as obligated by the registry protocol. The study was approved by the ethics committee of the Medical University of Warsaw and that patients provided written informed consent to participate in the study.

Given certain changes in clinical practice throughout the studied period, we decided to divide the study population into 3 groups. Group 1 (G1), early experience, procedures performed from March 2010 until the end of 2013. This period was characterised by no clinical practice guidelines or early introduction of the 2012 European Society of Cardiology (ESC) Valvular Heart Disease (VHD) guidelines. Also, first-generation bioprosthetic valves were used. Group 2 (G2), intermediate experience, from January 2014 until the end of 2016. Age of implementing 2012 ESC VHD guidelines with improved and new types of bioprosthesis being introduced. Group 3 (G3), recent experience, from January 2017 until July of 2019. Time of implementing the 2017 ESC VHD guidelines implementation and growing use of second-generation devices use.

\section{Data collection and definitions}

Data was acquired using the hospital electronic database and outpatient clinic charts. All patients with an unconfirmed status were followed up remotely by telephone visits. All definitions are in accordance with Valve Academic Research Consortium Criteria-2 [11].

\section{Statistical analysis}

The Shapiro-Wilk test was used to confirm or reject the normal distribution of each continuous variable. Continuous variables with normal distribution were presented as means (SD) and compared between three groups using ANOVA with Welch statistics. Tukey post-hoc analysis for ANOVA test was applied when appropriate. Continuous variables with non-normal distribution were presented as medians with interquartile range (IQR) and compared with the Kruskal-Wallis test. Categorical variables, expressed as counts and percentages, were compared using the Chisquare test or Fisher's exact test, as appropriate.
Kaplan-Meier curves and log-rank tests of the time-toevent data were used to assess the differences of 1-year all-cause mortality between the groups. Cox proportional hazard analysis was performed to find possible predictors of mortality in 1-year observation for all groups. All probability values reported are 2-sided and a value $<0.05$ was considered to be significant. Data were processed using the SPSS software, version 26 (IBM SPSS Statistics, NY, USA) and Medcalc, version 16 (MedCalc Software, Ostend, Belgium).

\section{RESULTS}

\section{Baseline clinical and echocardiographic characteristics}

After dividing into subgroups the population of $\mathrm{G} 1$ consisted of 130 patients, G2 and G3 of 164 and 212 patients, respectively. There were no significant between-group differences in terms of either mean age or percentage of the female sex (Table 1). There was however a clear decrease in logistic Euroscore values with $\mathrm{G} 3$ being of the lowest risk $(\mathrm{G} 1=14.0[8.4-20.2]$ vs $\mathrm{G} 2=12.0[7.0-22.2]$ vs G3 $=5.1$ [3.58.5]; $P<0.001)$. Patients in $\mathrm{G} 3$ also had higher rates of previous percutaneous interventions and the lowest frequency of previous coronary artery bypass grafting. The presence of peripheral artery disease changed with time. There were significant differences in baseline aortic valve area but not in terms of left ventricular ejection fraction (Table 1). Group 1 was characterized by the highest mean pressure gradient before TAVI (G1 = 47 [39-60] $\mathrm{mm} \mathrm{Hg}$ vs $\mathrm{G} 2=43$ [34-51] $\mathrm{mm}$ $\mathrm{Hg}$ vs $\mathrm{G} 3=43$ [34-51] $\mathrm{mm} \mathrm{Hg} ; P<0.001$ ) (Figure 1).

\section{Procedural characteristics}

Procedural management changed significantly during the analyzed time (Table 2). In G1 there were only 2 types of prostheses used (Corevalve $64.6 \%$ and Sapien/Sapien XT 34.6\%) with the biggest diversification of the devices reached in G2. In G3 there was a visible reversion into utilizing 2 types of valves, both of them being self-expandable (Evolut R/PRO 47.6\% and Portico 47.2\%).

Procedural anesthesia has also been significantly transformed - from $95.4 \%$ of cases done in general anesthesia in G1 to only $26.9 \%$ in G3 (replaced by conscious sedation). Time has brought a significant increase in applying trans-femoral access for TAVI with $91.5 \%$ of cases performed this way in G3. With the introduction of trans-carotid access 
Table 1. Baseline characteristics

\begin{tabular}{|c|c|c|c|c|c|}
\hline & All & $\begin{array}{c}\text { Group 1 } \\
(2010-2013)\end{array}$ & $\begin{array}{c}\text { Group 2 } \\
(2014-2016)\end{array}$ & $\begin{array}{c}\text { Group 3 } \\
(2017-2019)\end{array}$ & $P$-value \\
\hline Baseline characteristics & $n=506$ & $n=130$ & $n=164$ & $n=212$ & \\
\hline Age, years & $79.4(7)$ & $79.1(7.1)$ & $79.1(7.1)$ & $79.7(6.6)$ & 0.73 \\
\hline Female sex, $\mathrm{n}(\%)$ & $259(51.2)$ & $64(49.2)$ & $85(51.8)$ & $110(51.9)$ & 0.88 \\
\hline $\mathrm{BMI}, \mathrm{kg} / \mathrm{m}^{2}$, mean (SD) & $27.1(5)$ & $27.4(6)$ & $27.4(6)$ & $27(4.5)$ & 0.72 \\
\hline Logistic Euroscore, median (IQR) & $8.5(4.8-17.4)$ & $14.0(8.4-20.2)$ & $12.0(7.0-22.2)$ & $5.1(3.5-8.5)$ & $<0.001$ \\
\hline Hypertension, $\mathrm{n}(\%)$ & $400(79.1)$ & $97(74.6)$ & $128(78)$ & $175(82.5)$ & 0.21 \\
\hline Diabetes, $\mathrm{n}(\%)$ & $187(37)$ & $49(37.7)$ & 64 (39) & $74(34.9)$ & 0.70 \\
\hline CKD stage $>3, n(\%)$ & $52(10.3)$ & $17(13.1)$ & $18(11)$ & $17(8)$ & 0.21 \\
\hline COPD, n (\%) & $86(17)$ & $28(21.5)$ & $23(14)$ & $35(16.5)$ & 0.25 \\
\hline Atrial fibrillation, $\mathrm{n}(\%)$ & $189(37.4)$ & $48(36.9)$ & $56(34.1)$ & $85(40.1)$ & 0.47 \\
\hline $\mathrm{PCl}, \mathrm{n}(\%)$ & $148(29.2)$ & $35(26.9)$ & $37(22.6)$ & $76(35.8)$ & 0.01 \\
\hline CABG, $n(\%)$ & $59(11.7)$ & $15(11.5)$ & $28(17.1)$ & $16(7.5)$ & 0.02 \\
\hline $\mathrm{Ml}, \mathrm{n}(\%)$ & $107(21.1)$ & $36(27.7)$ & $35(21.3)$ & $36(17)$ & 0.07 \\
\hline Stroke, n (\%) & $67(13.2)$ & $24(18.5)$ & $17(10.4)$ & $26(12.3)$ & 0.12 \\
\hline Pacemaker, n (\%) & $86(17)$ & $20(15.4)$ & $27(16.5)$ & $39(18.4)$ & 0.78 \\
\hline PAD, n (\%) & $107(21.1)$ & $22(16.9)$ & $55(33.5)$ & $30(14.2)$ & $<0.001$ \\
\hline \multicolumn{6}{|l|}{ Baseline echocardiography } \\
\hline AVA, $\mathrm{cm}^{2}$, median (IQR) & $0.7(0.6-0.9)$ & $0.7(0.6-0.8)$ & $0.8(0.6-0.9)$ & $0.7(0.6-0.9)$ & 0.02 \\
\hline $\mathrm{EF}, \%$, median (IQR) & $55(45-64)$ & $52(40-60)$ & $55(45-65)$ & $58(46-63)$ & 0.08 \\
\hline Mean PG, mm Hg, median (IQR) & $44(34-53)$ & $47(39-60)$ & $43(34-51)$ & $43(34-51)$ & 0.003 \\
\hline
\end{tabular}

Abbreviations: $A V A$, aortic valve area; $B M I$, body mass index; $C A B G$, coronary-artery bypass grafting; $C K D$, chronic kidney disease; COPD, chronic obstructive pulmonary disease; $\mathrm{EF}$, ejection fraction; IQR, interquartile range; $\mathrm{MI}$, myocardial infarction; $\mathrm{PAD}$, peripheral artery disease; $\mathrm{PCI}$, percutaneous intervention; $\mathrm{PG}$, pressure gradient; $\mathrm{SD}$, standard deviation

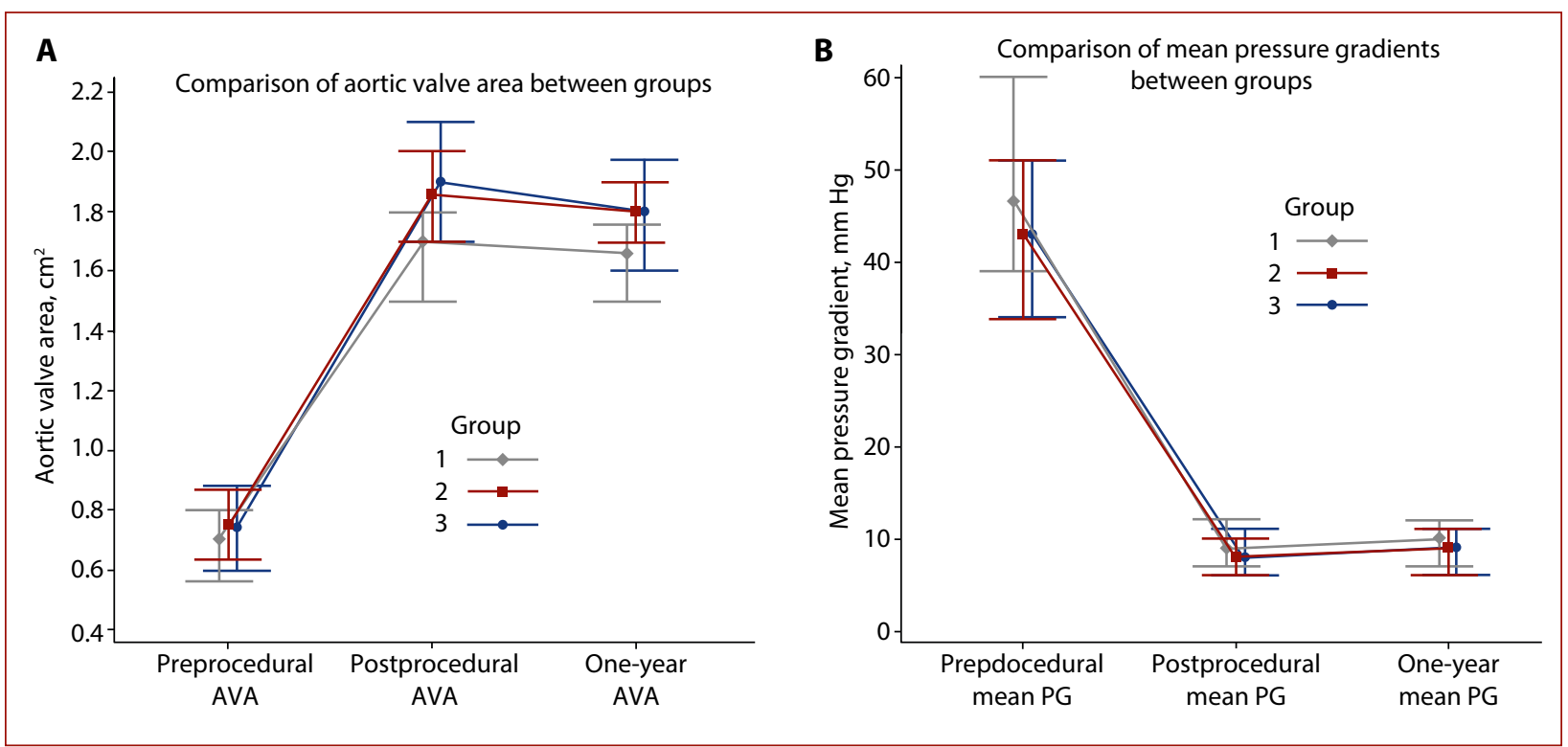

Figure 1. A. Comparison of aortic valve area (AVA); B. and mean pressure gradients.

Clustered multiple variables graphs of mean preassure gradients and aortic valve area presented as median with interquartile ranges. Pre-procedural AVA G1 $0.7(0.6-0.9) \mathrm{cm}^{2}$ vs G2 $0.7(0.6-0.8) \mathrm{cm}^{2}$ vs G3 $0.7(0.6-0.9) \mathrm{cm}^{2} ; P=0.02$. Post-procedural AVA G1 1.70 (1.5-1.8) $\mathrm{cm}^{2}$ vs G2 $1.86(1.7-2.0) \mathrm{cm}^{2}$ vs G3 $1.90(1.7-2.1) \mathrm{cm}^{2} ; P<0.001$. 1-year AVA: G1 1.66 (1.5-1.8) cm ${ }^{2}$ vs G2 1.80 (1.7-1.9) cm² vs G3 1.80 (1.6-2.0) $\mathrm{cm}^{2} ; P=0.002$. Pre-procedural MeanPG G1 $47(39-60) \mathrm{cm}^{2}$ vs G2 43 (34-51) $\mathrm{cm}^{2}$ vs G3 43 (34-51) $\mathrm{cm}^{2} ; P=0.003$. Post-procedural MeanPG G1 9 (7-12) cm² vs G2 8 (6-10) $\mathrm{cm}^{2}$ vs G3 $8(6-11) \mathrm{cm}^{2} ; P=0.002$. One-year MeanPG: G1 10 (7-12) cm² vs G2 9 (6-11) cm² vs G3 9 (6-11) cm², $P=0.19$

in late 2014 [12], more invasive trans-apical and direct-aortic access were gradually withdrawn. With higher rates of application of trans-femoral access came wider use of percutaneous closing devices (Prostar XL in G1, Prostar XL and Proglide in G2 and Proglide in G3) reaching $84.9 \%$ in G3.

There has been a gradual decrease in using predilatation before valve implantation $(93.8 \%$ in $\mathrm{G} 1$ to $59.9 \%$ in G3) with a parallel increase in postdilatation $(20.8 \%$ in $\mathrm{G} 1$ to $35.8 \%$ in G3). The procedural time was shortened and contrast use decreased (Table 2).

\section{Echocardiographic follow-up}

All patients achieved significant improvement in the aortic valve area (AVA), which was sustained in 1-year observation 
Table 2. Procedural characteristics

\begin{tabular}{|c|c|c|c|c|c|}
\hline & All & $\begin{array}{c}\text { Group } 1 \\
(2010-2013)\end{array}$ & $\begin{array}{c}\text { Group } 2 \\
(2014-2016)\end{array}$ & $\begin{array}{c}\text { Group } 3 \\
(2017-2019)\end{array}$ & $\boldsymbol{P}$-value \\
\hline Prosthesis type & $n=506$ & $n=130$ & $n=164$ & $n=212$ & \\
\hline Corevalve, n (\%) & $116(22.9)$ & $84(64.6)$ & $32(19.5)$ & $0(0)$ & $<0.001$ \\
\hline Sapien/Sapien XT, n (\%) & $76(15)$ & $45(34.6)$ & 31 (18.9) & $0(0)$ & $<0.001$ \\
\hline Sapien 3, n (\%) & $2(0.4)$ & $0(0)$ & $0(0)$ & $2(0.9)$ & 0.25 \\
\hline Lotus, n (\%) & $34(6.7)$ & $0(0)$ & $27(16.5)$ & $7(3.3)$ & $<0.001$ \\
\hline Evolut R/PRO, n (\%) & $167(33)$ & $0(0)$ & $66(40.2)$ & $101(47.6)$ & $<0.001$ \\
\hline Portico, n (\%) & $104(20.6)$ & $0(0)$ & $4(2.4)$ & $100(47.2)$ & $<0.001$ \\
\hline Other ${ }^{\mathrm{a}}, \mathrm{n}(\%)$ & $7(1.4)$ & $1(0.8)$ & $4(2.4)$ & $2(0.9)$ & 0.82 \\
\hline \multicolumn{6}{|l|}{ Access } \\
\hline Femoral, n (\%) & $429(84.8)$ & $96(73.8)$ & $139(84.8)$ & $194(91.5)$ & $<0.001$ \\
\hline Subclavian, n (\%) & $19(3.8)$ & $10(7.7)$ & $2(1.2)$ & $7(3.3)$ & 0.01 \\
\hline Carotid, n (\%) & $25(4.9)$ & $0(0)$ & $14(8.5)$ & $11(5.2)$ & 0.003 \\
\hline Transapical, n (\%) & $9(1.8)$ & $6(4.6)$ & $3(1.8)$ & $0(0)$ & 0.007 \\
\hline Direct aortic, n (\%) & $24(4.7)$ & $18(13.8)$ & $6(3.7)$ & $0(0)$ & $<0.001$ \\
\hline \multicolumn{6}{|l|}{ Procedure } \\
\hline Predilatation, n (\%) & $351(69.4)$ & $122(93.8)$ & $102(62.2)$ & $127(59.9)$ & $<0.001$ \\
\hline Postdilatation, n (\%) & $165(32.6)$ & $27(20.8)$ & $62(37.8)$ & $76(35.8)$ & 0.003 \\
\hline Procedure time ${ }^{\mathrm{b}}, \min (\mathrm{IQR})$ & $150(100-200)$ & $208(163-240)$ & $165(140-190)$ & $100(80-150)$ & $<0.001$ \\
\hline Contrast, ml & $204.9(72.1)$ & $214.6(67.3)$ & $208.5(72.4)$ & $193(74.3)$ & 0.03 \\
\hline Radiation dose, mGy (IQR) & 1212 (789-1980) & $1160(800-1855)$ & $1254(803-2066)$ & 1224 (719-1965) & 0.63 \\
\hline \multicolumn{6}{|l|}{ Anesthesia } \\
\hline General anesthesia, n (\%) & $301(59.5)$ & $124(95.4)$ & $120(73.2)$ & $57(26.9)$ & $<0.001$ \\
\hline Conscious sedation, n (\%) & $205(40.5)$ & $6(4.6)$ & $44(26.8)$ & $155(73.1)$ & $<0.001$ \\
\hline \multicolumn{6}{|l|}{ Access closure } \\
\hline Percutaneous, n (\%) & $380(75.1)$ & $81(62.3)$ & $119(72.6)$ & $180(84.9)$ & $<0.001$ \\
\hline Surgical, n (\%) & $126(24.9)$ & $49(37.7)$ & $45(27.4)$ & $32(15.1)$ & $<0.001$ \\
\hline
\end{tabular}

a Other valves used were Engager, Allegra, JenaValve, and Accurate Neo.

'Time measured from patients arrival at the cath lab or hybrid room until leaving, includes anesthetic preparations

(Figure 1). There were between-group differences in terms of post-procedural and 1-year AVA with lowest values recorded for G1 (post-procedural AVA: G1 $1.70[1.5-1.8] \mathrm{cm}^{2}$ vs G2 $1.86[1.7-2.0] \mathrm{cm}^{2}$ vs G3 $1.90[1.7-2.1] \mathrm{cm}^{2} ; P<0.001$; 1-year AVA: G1 $1.66[1.5-1.8] \mathrm{cm}^{2}$ vs G2 $1.80[1.7-1.9] \mathrm{cm}^{2}$ vs G3 $\left.1.80[1.6-2.0] \mathrm{cm}^{2}, P=0.002\right)$. Sustained reduction in mean transvalvular gradients with no significant differences between groups was observed (Figure 1).

\section{Functional status}

Almost two-thirds of patients referred to TAVI were severely symptomatic (NYHA class III and IV) (Figure 2). In $67.6 \%$ of cases performing TAVI helped to completely relieve the signs of heart failure (NYHA I) or leave only minor symptoms (NYHA II 24.1\%). This positive effect was maintained in survivors at 1-year observation (NYHA I in $72.4 \%$ and NYHA II in $21.3 \%$ of cases).

\section{Clinical outcomes and 1-year mortality}

Postprocedural outcomes improved significantly over time in terms of reducing major or life-threatening bleeding (G1 26.9\%, G2 12.8\%, G3 9.4\%; $P<0.001$ ), major vascular complications (G1 15.4\%, G2 8.5\%, G3 5.7\%; $P=0.02$ ), and moderate to severe paravalvular leakage (G1 16.2\%, G2 11\%, G3 7.5\%; $P=0.046$ ) (Table 3). Moreover, patients in $\mathrm{G} 3$ had the shortest length of hospital stay. On the other hand, stroke rate and need for permanent pacemaker implantation did not decrease with time (Table 3).

During the 12-month follow-up after TAVI, mortality from all causes was significantly lower in G3 (9.1\%) as compared with G1 (20\%; $P=0.004)$ and G2 $(17.7 \% ; P=0.02)$ (Figure 3). In the Cox proportional-hazards model, chronic kidney disease stage $>3$ and post-TAVI stroke were independently correlated with 1-year mortality. Femoral access had the potential of improving 1-year survival as compared with non-transfemoral delivery routes (Table 4).

\section{DISCUSSION}

This analysis demonstrates that TAVI has been constantly evolving over the last decade. Starting with baseline characteristics, it is apparent that the approval of lower-risk groups in the guidelines has been subsequently implemented in real-life settings and reflected by lower values of logistic Euroscore. However, this change was not derived from decreasing patients'age, which throughout the whole study was almost constant and close to 80 years on average, but rather from the smaller burden of concomitant diseases (e.g. fewer history of coronary artery bypass grafting, myocardial infarction, stroke, chronic kidney disease (CKD) and better baseline left ventricle function). This observation is in line with the results of randomized trials and registries, which compared TAVI and SAVR in populations with in- 
Table 3. Clinical outcomes

\begin{tabular}{|c|c|c|c|c|c|}
\hline & All & $\begin{array}{c}\text { Group 1 } \\
(2010-2013)\end{array}$ & $\begin{array}{c}\text { Group 2 } \\
\text { (2014-2016) }\end{array}$ & $\begin{array}{c}\text { Group 3 } \\
(2017-2019)\end{array}$ & \multirow[t]{2}{*}{$P$-value } \\
\hline & $\mathrm{n}=506$ & $n=130$ & $n=164$ & $n=212$ & \\
\hline Hospital stay, days median (IQR) & $10(4-18)$ & $15(7-24)$ & $11(7-17)$ & $7(4-14)$ & $<0.001$ \\
\hline Moderate or severe PVL, n (\%) & $55(10.9)$ & $21(16.2 \%)$ & $18(11 \%)$ & $16(7.5 \%)$ & 0.046 \\
\hline Major or life-threatening bleeding, $n(\%)$ & $76(15)$ & $35(26.9 \%)$ & $21(12.8 \%)$ & $20(9.4 \%)$ & $<0.001$ \\
\hline Major vascular complications, $\mathrm{n}(\%)$ & $46(9.1)$ & $20(15.4 \%)$ & $14(8.5 \%)$ & $12(5.7 \%)$ & 0.02 \\
\hline Stroke, $\mathrm{n}(\%)$ & $17(3.4)$ & $5(3.8 \%)$ & $4(2.4 \%)$ & $8(3.8 \%)$ & 0.40 \\
\hline TIA & $8(1.6)$ & $2(1.5 \%)$ & $4(2.4 \%)$ & $2(0.9 \%)$ & 0.37 \\
\hline Permanent pacemaker, $\mathrm{n}(\%)$ & $84(16.6)$ & $22(16.9 \%)$ & $24(14.6 \%)$ & $38(17.9 \%)$ & 0.63 \\
\hline 30-day all-cause mortality, n (\%) & $34(6.7)$ & $10(7.7 \%)$ & $15(9.1 \%)$ & $9(4.2 \%)$ & 0.28 \\
\hline
\end{tabular}

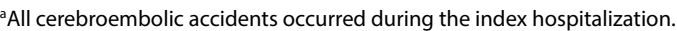

Abbreviations: IQR, interquartile range; PVL, paravalvular leak; TIA, transient ischemic attack. All definitions according to VARC-2 criteria

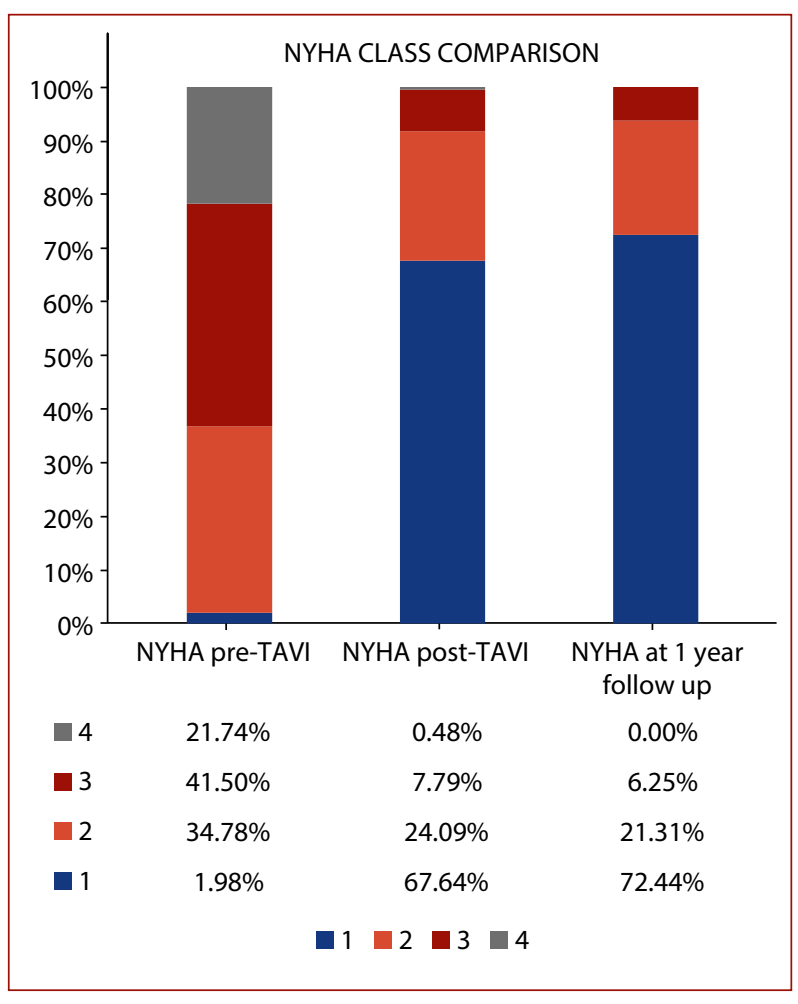

Figure 2. Functional status before and after TAVI.

Abbreviations: $\mathrm{Cl}$, confidence interval; $\mathrm{HR}$, hazard ratio; NYHA, New York Heart Association

termediate surgical risk $[13,14]$. Also of note, in the early experience period, significantly higher mean transvalvular pressure gradients prior to the procedure were noted - possibly due to earlier referral and/or broader inclusion of low-flow, low-gradient AS at 2017-2019 period [15].

Throughout the years, broadening of indications for TAVI was accompanied by some relevant modifications in the periprocedural technique - reflected mostly by wide utilization of transfemoral access (over 90\%) and conscious sedation (almost 75\%) in our recent experience period. Significant improvements in delivery systems (size reduction and flexibility) and bioprothesis design (repositionability and sealing cuffs) available from a part of inter-
Table 4. Cox proportional hazard analysis for 1-year all-cause mortality analysis

\begin{tabular}{l|c|c|c|c|} 
& \multirow{2}{*}{ P-value } & \multirow{2}{*}{ HR } & \multicolumn{2}{|c}{ 95\% CI } \\
\cline { 4 - 5 } & & & Low & Upper \\
\hline CKD stage $>3$ & 0.007 & 2.205 & 1.236 & 3.935 \\
Femoral access & 0.02 & 0.515 & 0.3 & 0.885 \\
Post-TAVI stroke & 0.02 & 2.709 & 1.167 & 6.291 \\
\hline
\end{tabular}

Abbreviations: $\mathrm{Cl}$, confidence interval; $\mathrm{CKD}$, chronic kidney disease; $\mathrm{HR}$, hazard ratio

mediate and recent experience (part of G2 and G3) were most probably behind the gradual reduction of clinically relevant post-procedural complications: e.g. major and life-threatening bleeding, major vascular complications and paravalvular regurgitation - all of which negatively impact survival after TAVI [16-21]. Also, growing experience with newer devices was the probable reason for the shortening of procedural time and lesser amounts of the contrast used. Despite best efforts some complications did not improve with time - the need for permanent pacemaker implantation remained quite substantial and close to $20 \%$ - although this can be perceived as a normal rate with self-expanding prostheses (at least before new "cusp overlap" implantation techniques were introduced, which is after the analyzed periods), which accounted for $100 \%$ of bioprostheses in $\mathrm{G} 3$.

It can be hypothesized that decreasing surgical risk (especially observed in recent experience period G3) combined with multifactorial improvements in periprocedural care and prosthesis implantation are the reasons behind better 1-year survival exceeding $90 \%$ in G3. Importantly, 2 independent risk factors for 1-year mortality were found, i.e. baseline CKD stage $>3$ and post-procedural stroke. As the first baseline factor is non-modifiable or only partly modifiable, the latter at least theoretically could be prevented or minimized. The rate of stroke was comparable with those described elsewhere, but considering its negative impact on quality of life and mortality, preventive measures, namely brain protection devices, although still not recommended, should be strongly considered in the future for selected individuals $[22,23]$. 


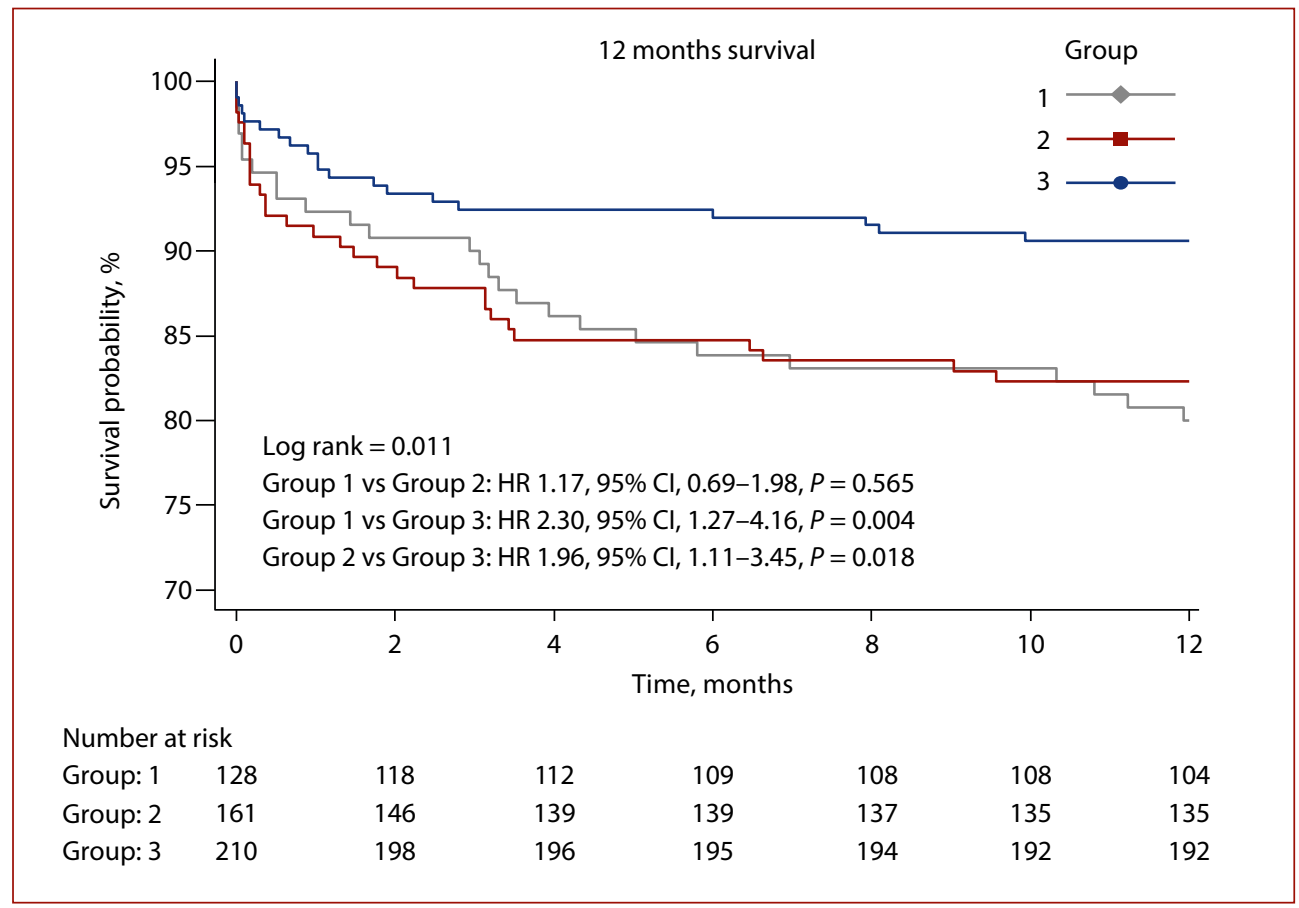

Figure 3. Kaplan-Meier curve with time-to-event analysis for 12-month survival in groups

In our dataset, we observed a clear survival improvement in short-term observation accompanied by stable echocardiographic parameters up to 1 year. The aim of future studies and registries should also focus on the assessment of long-term bioprosthetic performance [24, 25].

\section{Limitations}

First, the obvious disadvantage of the current study is its retrospective nature, which is always burdened with its inherent limitations. Second, the larger cohort of TAVI recipients would allow for a more comprehensive analysis on a year-by-year basis and could point at more independent predictors of mortality. However, the present dataset is one of the largest in Poland to date. Finally, since the intermediate experience period, only self-expanding bioprostheses were available with their unique advantages and limitations.

\section{CONCLUSIONS}

Transcatheter aortic valve implantation has grown from an innovative intervention reserved only for highest-risk or inoperable patients with severe AS into an almost default procedure in elderly patients irrespective of baseline risk. Interestingly, the age of TAVI recipients remained unchanged over the last decade and did not add to the overall risk reduction. Decreasing surgical risk coupled with improvements in delivery systems, bioprosthesis design, implantation technique, and periprocedural care resulted in fewer complications and better 1-year survival in the 2017-2019 period.

\section{Article information}

Conflict of interest: $\mathrm{ZH}$ received proctoring and consulting fees from Medtronic and Abbott. JK received proctoring and consulting fees from Medtronic and Abbott. Other authors have no potential conflict of interest.

Open access: This article is available in open access under Creative Common Attribution-Non-Commercial-No Derivatives 4.0 International (CC BY-NC-ND 4.0) license, allowing to download articles and share them with others as long as they credit the authors and the publisher, but without permission to change them in any way or use them commercially. For commercial use, please contact the journal office at kardiologiapolska@ptkardio.pl.

How to cite: Huczek Z, Rymuza B, Mazurek M, et al. Temporal trends of transcatheter aortic valve implantation in a high-volume academic center over 10 years. Kardiol Pol. 2021; 79(7-8): 820-826, doi: 10.33963/KP.a2021.0030.

\section{REFERENCES}

1. Zembala M, Wilczek K, Przybylski R, et al. POL-TAVI First — Polish report on transcatheter aortic valve implantation (TAVI) of Edwards-Sapien prosthesis in the first 19 high risk patients with severe aortic stenosis and comorbidities [article in Polish]. Kardiol Pol. 2009;67(8): 936-940, indexed in Pubmed: 19784896.

2. Kleczyński P, Bagieński M, Sorysz D, et al. Short- and intermediate-term improvement of patient quality of life after transcatheter aortic valve implantation: a single-centre study. Kardiol Pol. 2014; 72(7):612-616, doi: 10.5603/KP.a2014.0065, indexed in Pubmed: 24671914.

3. Wilczek K, Chodór P, Przybylski R, et al. First in Poland transcatheter, transfemoral aortic valve implantation in elderly symptomatic high-risk patient with aortic stenosis - novel Zabrze experience [article in Polish]. Kardiol Pol. 2009; 67(2): 219-223, indexed in Pubmed: 19288389.

4. Smith CR, Leon MB, Mack MJ, et al. PARTNER Trial Investigators, PARTNER Trial Investigators. Transcatheter versus surgical aortic-valve replacement in high-risk patients. N Engl J Med. 2011; 364(23): 2187-2198, doi: 10.1056/NEJMoa1103510, indexed in Pubmed: 21639811. 
5. Leon MB, Smith CR, Mack MJ, et al. Transcatheter or surgical aortic-valve replacement in intermediate-risk patients. N Engl J Med. 2016; 374(17): 1609-1620, doi: 10.1056/NEJMoa1514616, indexed in Pubmed: 27040324.

6. Kodali S, Williams M, Smith C, et al. Two-year outcomes after transcatheter or surgical aortic-valve replacement. N Engl J Med. 2012; 366(18): 1686-1695, doi: 10.1056/nejmoa1200384, indexed in Pubmed: 22443479.

7. Vahanian A, Alfieri $O$, Andreotti $F$, et al. Guidelines on the management of valvular heart disease (version 2012): the Joint Task Force on the Management of Valvular Heart Disease of the European Society of Cardiology (ESC) and the European Association for Cardio-Thoracic Surgery (EACTS). Kardiol Pol. 2012; 70(Suppl VII): S319-S372.

8. Baumgartner H, Falk V, Bax J, et al. 2017 ESC/EACTS Guidelines for the management of valvular heart disease. Kardiol Pol. 2018; 76(1): 1-62, doi: $10.5603 / \mathrm{kp} .2018 .0013$.

9. Di Mario C, Eltchaninoff $\mathrm{H}$, Moat N, et al. The 2011-12 pilot european sentinel registry of transcatheter aortic valve implantation: in-hospital results in 4,571 patients. Eurolntervention. 2013; 8(12): 1362-1371, doi: 10.4244/eijv8i12a209, indexed in Pubmed: 23256965.

10. Zembala-John J, Wilczek K, Tobota Z, et al. POL-TAVI - Polish Registry of Transcatheter Aortic Valve Implantation - simple tool, great value, rationale and design. Kardiochir Torakochirurgia Pol. 2016; 13(4):309-315 doi: 10.5114/kitp.2016.64870, indexed in Pubmed: 28096826.

11. Kappetein AP, Head SJ, Généreux $P$, et al. Updated standardized endpoint definitions for transcatheter aortic valve implantation: the Valve Academic Research Consortium-2 consensus document. Eur Heart J. 2012; 33(19): 2403-2418, doi: 10.1093/eurheartj/ehs255, indexed in Pubmed: 23026477.

12. Huczek Z, Wilimski R, Kochman J, et al. Common carotid artery access for transcatheter aortic valve implantation. Kardiol Pol. 2015; 73(7):478-484, doi: 10.5603/KP.2015.0122, indexed in Pubmed: 26189468.

13. Auffret $V$, Lefevre T, Van Belle $E$, et al. FRANCE TAVI Investigators. Temporal trends in transcatheter aortic valve replacement in France: FRANCE 2 to FRANCE TAVI. J Am Coll Cardiol. 2017; 70(1): 42-55, doi: 10.1016/j. jacc.2017.04.053, indexed in Pubmed: 28662806.

14. Bekeredjian R, Szabo G, Balaban Ü, et al. Patients at low surgical risk as defined by the Society of Thoracic Surgeons Score undergoing isolated interventional or surgical aortic valve implantation: in-hospital data and 1-year results from the German Aortic Valve Registry (GARY). Eur Heart J. 2019; 40(17): 1323-1330, doi: 10.1093/eurheartj/ehy699, indexed in Pubmed: 30445543.

15. Zbroński K, Huczek Z, Gawalko M, et al. Paradoxical low-flow aortic stenosis - baseline characteristics, impact on mortality. Postepy Kardiol Interwencyjnej. 2019; 15(1): 13-19, doi: 10.5114/aic.2019.83770, indexed in Pubmed: 31043980.
16. Huczek Z, Kochman J, Kowara MK, et al. Baseline platelet indices and bleeding after transcatheter aortic valve implantation. Blood Coagul Fibrinolysis. 2015; 26(5):527-532, doi: 10.1097/MBC.0000000000000283, indexed in Pubmed: 25811449.

17. Kochman J, Rymuza B, Huczek Z, et al. Incidence, predictors and impact of severe periprocedural bleeding according to VARC-2 criteria on 1-year clinical outcomes in patients after transcatheter aortic valve implantation. Int Heart J. 2016; 57(1): 35-40, doi: 10.1536/ihj.15-195, indexed in Pubmed: 26673439.

18. Grodecki K, Zbroński K, Przybyszewska-Kazulak E, et al. Pre-procedural abnormal function of von Willebrand Factor is predictive of bleeding after surgical but not transcatheter aortic valve replacement. J Thromb Thrombolysis. 2019; 48(4): 610-618, doi: 10.1007/s11239-019-01917-7, indexed in Pubmed: 31359325.

19. Rymuza B, Zbroński K, Scisło P, et al. Thromboelastography for predicting bleeding in patients with aortic stenosis treated with transcatheter aortic valve implantation. Kardiol Pol. 2018; 76(2): 418-425, doi: 10.5603/KP.a2017.0225, indexed in Pubmed: 29192952.

20. Zbroński K, Huczek Z, Puchta D, et al. Outcome prediction following transcatheter aortic valve implantation: multiple risk scores comparison. Cardiol J. 2016; 23(2): 169-177, doi: 10.5603/CJ.a2015.0081, indexed in Pubmed: 26711463.

21. Huczek Z, Kochman J, Rymuza B, et al. Paravalvular aortic regurgitation as the reason for second CoreValve bioprosthesis implantation in a patient with native bicuspid valve. Kardiol Pol. 2013; 71(11): 1211, doi: 10.5603/KP.2013.0311, indexed in Pubmed: 24297728.

22. Muralidharan A, Thiagarajan K, Van Ham R, et al. Meta-analysis of perioperative stroke and mortality in transcatheter aortic valve implantation. Am J Cardiol. 2016; 118(7): 1031-1045, doi: 10.1016/j.amjcard.2016.07.011, indexed in Pubmed: 27634034.

23. Thirumala PD, Nguyen FD, Mehta A, et al. Perioperative stroke, in-hospital mortality, and postoperative morbidity following transcatheter aortic valve implantation: a nationwide study. J Clin Neurol. 2017; 13(4):351-358, doi: 10.3988/jen.2017.13.4.351, indexed in Pubmed: 28884980.

24. Sorysz D, Dziewierz A, Bagieński $M$, et al. Early results of the ongoing Polish Registry of Valve Thrombosis after Transcatheter Aortic Valve Implantation (ZAKPOLTAVI). Kardiol Pol. 2020; 78(7-8): 681-687, doi: 10.33963/KP.15426, indexed in Pubmed: 32543799.

25. Piroli F, Franchin L, Bruno F, et al. New advances in the prevention of transcatheter aortic valve implantation failure: current and future perspectives. Kardiol Pol. 2020; 78(9): 842-849, doi: 10.33963/KP.15522, indexed in Pubmed: 32692029. 